\title{
Junk Food Consumption and Its Association with Body Mass Index Among School Adolescents
}

\author{
Pramila Poudel \\ Department of Nursing, National Medical College and Teaching Hospital, Birgunj, Nepal \\ Email address: \\ pdlpramila123@yahoo.com \\ To cite this article: \\ Pramila Poudel. Junk Food Consumption and Its Association with Body Mass Index Among School Adolescents. International Journal of \\ Nutrition and Food Sciences. Vol. 7, No. 3, 2018, pp. 90-93. doi: 10.11648/j.ijnfs.20180703.12
}

Received: March 16, 2018; Accepted: April 3, 2018; Published: May 9, 2018

\begin{abstract}
Healthy and nutritious food are being replaced by new commercial food items called Junk Food. These food item are with high calories but with low nutritive values. Excess consumption of junk food is associated with several nutritional problems ranging from underweight to obesity and various Non-communicable diseases. The study was conducted to assess the general junk food consumption habits, pattern and its association with Body Mass Index among adolescents. A descriptive cross sectional design was adopted to collect data among 311 adolescents studying in grade $8 \& 9$ of selected private school at, Parsa, Nepal using a pretested structured self-administered questionnaire. The obtained data were analyzed by descriptive and inferential statistics using SPSS 16 version. The result of the study revealed that age range of adolescents was 12-17 years. $37 \%$ of the adolescents were in the age group of 15 years. The BMI value was $18.81 \pm 2.35$ whereas majority $50.5 \%$ of the adolescents was having BMI less than normal and were considered underweight. The time of junk food consumption is significantly associated with BMI with ( $p$ value 0.02 ) and amount of money spend on junk food is also associated with BMI with ( $p$ value 0.006 ). Junk food consumption is significantly associated with low BMI among adolescents. Only a limited numbers of adolescents have understood that excess consumption of junk food has negative effects on general health. This study may contribute to provide awareness regarding the consequences of junk food consumption along with setting limits over junk food by parents and teachers to promote healthy dietary habits among adolescents.
\end{abstract}

Keywords: Junk Food, BMI, Adolescents

\section{Introduction}

Junk food is "designed for ready availability, use, or consumption with little consideration given to quality or significance" [1]. Low intake of nutrients and increased consumption of high-energy foods is known as junk food. It represents a significant proportion (15-40\%) of total daily caloric intake of children and has been supposed to be associated with overweight and obesity [2]. BMI is a measure of how appropriate a person's weight, is for his/her height. Based on BMI, obesity is divided into different classes; normal range (18.5-24.9), below normal range $(<18.5)$, preobesity (25-29.9), obesity class I (30-34.9), obesity class II (35-39.9) [3].

Now a day healthy and hygienic nutritious food has been substituted by the new food preferences - JUNK FOOD. In the present world economy, junk food is a global concern. It is an integral part of life in the developed and also the developing world, bringing along with it is a gross increase in obesity and associated problems [4]. As lifestyles and dietary habits are changing, people from different age group, society especially children and adolescents are attracted towards consuming fast food [5].

A study done in AIIMS had shown that consumption of junk food has been increased among adolescents. Same study revealed that this trend and associated lifestyle factors in the urban adolescent and young adult population had resulted in the increase in nutritional problems and various noncommunicable diseases [6]. Therefore; the study was conducted to find out the consuming pattern of junk food among school adolescents and its association with their Body Mass Index. 


\section{Materials and Methods}

\subsection{Study Area and Population}

This study was conducted in a private school located at Birgunj sub Metropolitan, a commercial city which lies in Parsa district of Nepal. Nepal is a developing Asian country which has recently entered from its unitary system into a new "Federal Democratic Republic System". The study population was adolescents studying in grade 8 and 9 .

\subsection{Type of Study}

A descriptive cross sectional study was conducted among adolescents to identify their pattern of junk food consumption and its association with Body Mass Index.

\subsection{Sample Size Determination and Sampling Technique}

A representative sample size of 311 was obtained using nonprobability purposive sampling method and the sample size was calculated at $95 \%$ confidence level and $5 \%$ confidence interval and derived in the formula $\left(n=Z^{2} P Q / d^{2}\right)$. The prevalence of obesity determined by BMI among adolescents is $29.7 \%$ [7].

\subsection{Data Collection and Analysis}

Data was collected from selected adolescents at the month of February 2018 using A pretested structured selfadministered questionnaire $(\mathrm{r}=0.81)$. The questionnaire consisted of three (3) sections. Section A consisted of 8 questions related to socio-demographic characteristics of the participants while Section B consisted 11 Question related to general junk food habits and section $\mathrm{C}$ consisted 5 Question related to junk food consumption pattern among adolescents. Height and weight was taken using standard scales and the findings were given to the students to fill in their questionnaire. BMI was calculated later in the main sheet. The collected data was organized coded and entered in MsExcel and imported to SPSS 16 version for further statistical analysis.

\subsection{Ethical Considerations}

Ethical clearance from Institutional Review Committee of National medical College \& Teaching Hospital and administrative approval from the principal of selected school was obtained prior to data collection.

\section{Results}

The result of the study revealed that age range of adolescents was $12-17$ years. $37 \%$ of the adolescents were in the age group of 15 years. Regarding sex $66.9 \%$ were male and remaining $33 \%$ were female. Similarly, majority $52.1 \%$ were studying in grade nine and remaining $47.9 \%$ were in grade 8 . Meanwhile, majority $87.1 \%$ of adolescent were following Hindu religion. Regarding parental education 35\% of the fathers were secondary educated and $35 \%$ of mothers were primary educated. Maximum $76.5 \%$ of adolescents were residing in their own home. Regarding income $43.7 \%$ of adolescents had 20001-50000 Nrs as monthly family income.

Maximum $65.5 \%$ of adolescents answered that junk food is unhealthy and unhygienic food. Similarly, 70.1\% reported that homemade food is the most preferred food item as compared to other food item. $48.9 \%$ answered that fast food is their most favorite junk food. Meanwhile, $41.5 \%$ of adolescents check junk food for quality and 34.7\% reported that they never check nutrient fact level in packaged junk food. Majority, $73.65 \%$ of adolescents preferred junk food as they are tasty. Meanwhile, $46 \%$ adolescent's gets junk food from general stores and majority $64.6 \%$ of them take junk food with their friends at school. Similarly $59.5 \%$ of adolescents answered that their parents try to keep healthy food at home or tiffin. Only $39.5 \%$ of adolescents had understood that excess consumption of junk food may lead to health problems.

Table 1. Food Consumption Pattern.

\begin{tabular}{|c|c|c|}
\hline Variables & Frequency & Percentage \\
\hline \multicolumn{3}{|c|}{$\begin{array}{l}\text { Do you consume junk food as alternative to } \\
\text { regular meal? }\end{array}$} \\
\hline Yes & 76 & 24.4 \\
\hline No & 235 & 75.6 \\
\hline \multicolumn{3}{|c|}{$\begin{array}{l}\text { What is the Most usual time you consume } \\
\text { junk food? }\end{array}$} \\
\hline Before school as breakfast & 18 & 5.8 \\
\hline At school during lunch & 127 & 40.8 \\
\hline After school & 72 & 23.2 \\
\hline Whenever available & 94 & 30.2 \\
\hline \multicolumn{3}{|l|}{$\begin{array}{l}\text { How many time son average do you } \\
\text { consume junk food? }\end{array}$} \\
\hline everyday & 105 & 33.8 \\
\hline Once a week & 69 & 22.2 \\
\hline Twice a week & 77 & 24.8 \\
\hline Several times & 60 & 19.3 \\
\hline \multicolumn{3}{|c|}{$\begin{array}{l}\text { On average how much do you expect to pay } \\
\text { for junk food at a time? }\end{array}$} \\
\hline$>20 \mathrm{Rs}$ & 101 & 32.5 \\
\hline $21-50 \mathrm{Rs}$ & 112 & 36.0 \\
\hline 51-100 Rs & 69 & 22.2 \\
\hline 101 Rs and above & 29 & 9.3 \\
\hline \multicolumn{3}{|c|}{$\begin{array}{l}\text { What is most common junk food you } \\
\text { consume? }\end{array}$} \\
\hline Fast food (momo, chowmin etc) & 122 & 39.2 \\
\hline Aerated drinks (coke, fanta) & 15 & 4.8 \\
\hline Street food (pakora, pani puri) & 42 & 13.5 \\
\hline Candies, biscuits, chips, noodles & 132 & 42.4 \\
\hline
\end{tabular}

Table 1 depicts that maximum $75.6 \%$ of adolescent does not consume junk food as alternative ti regular meal. Meanwhile $40.8 \%$ adolescents answered that they mostly consume junk food at school during lunch. Similarly, 33.8\% of adolescents consumes junk food everyday on average and $36 \%$ adolescents spends $21-50$ Rs on average to buy junk food at a time. Whereas $42.45 \%$ reported that candies, biscuits, chips, noodles is the most common junk food they consume. 
Table 2. Body Mass Index.

\begin{tabular}{lll}
\hline BMI & Frequency & Percentage \\
\hline$<18.5$ (underweight) & 157 & 50.5 \\
18.5 to 24.9 (normal) & 147 & 47.3 \\
$>25$ (overweight) & 7 & 2.3 \\
\hline
\end{tabular}

Table 2 reveals that majority $50.5 \%$ of the adolescents were having BMI less than normal and were considered underweight.

Table 3. Mean Score of BMI.

\begin{tabular}{llll}
\hline Variable & Mean \pm SD & Mean Percentage & Range \\
\hline BMI & $18.8198 \pm 2.3579$ & 53.63 & $35.09-13.67$ \\
\hline
\end{tabular}

Table 3 reveals that the mean percentage of BMI is 53.63.

Table 4. Association between Junk Food Consumption with BMI.

\begin{tabular}{|c|c|c|c|c|c|}
\hline \multirow[t]{2}{*}{ Variable } & \multicolumn{3}{|l|}{ BMI } & \multirow{2}{*}{$x^{2}$} & \multirow{2}{*}{ p-Value } \\
\hline & $<18.5$ & 18.5 to 24.9 & $>\mathbf{2 5}$ & & \\
\hline \multicolumn{6}{|c|}{ Do you consume junk food as alternative to regular meal? } \\
\hline Yes & $41(53.9)$ & $35(46.1)$ & $0(0.0)$ & 4.736 & $0.94 *$ \\
\hline No & $116(49.4)$ & $111(47.2)$ & $8(2.4)$ & & \\
\hline \multicolumn{6}{|c|}{ What is the Most usual time you consume junk food? } \\
\hline Before school as breakfast & $7(38.9)$ & $9(50.0)$ & $2(11.1)$ & 0.594 & $0.02 *$ \\
\hline At school during lunch & $60(47.2)$ & $67(52.8)$ & $0(0.0)$ & & \\
\hline After school & $41(56.9)$ & $30(41.7)$ & $1(1.4)$ & & \\
\hline Whenever available & $49(52.1)$ & $40(42.6)$ & $5(5.3)$ & & \\
\hline \multicolumn{6}{|c|}{ How many times on average do you consume junk food? } \\
\hline everyday & $54(51.4)$ & $49(46.7)$ & $2(1.9)$ & 1.431 & $0.964 *$ \\
\hline Once a week & $33(47.8)$ & $33(47.8)$ & $3(4.3)$ & & \\
\hline Twice a week & $38(49.4)$ & $37(48.1)$ & $2(2.6)$ & & \\
\hline Several times & $32(53.3)$ & $27(45.0)$ & $1(1.5)$ & & \\
\hline \multicolumn{6}{|c|}{ On average how much do you expect to pay for junk food at a time? } \\
\hline$>20 \mathrm{Rs}$ & $62(61.4)$ & $38(37.60)$ & $1(1.0)$ & 7.561 & $0.006^{* *}$ \\
\hline $21-50 \mathrm{Rs}$ & $54(48.2)$ & $56(50.0)$ & $2(1.8)$ & & \\
\hline $51-100 \mathrm{Rs}$ & $28(40.6)$ & $38(55.1)$ & $3(4.3)$ & & \\
\hline 101 Rs and above & $13(44.8)$ & $15(51.7)$ & $1(3.4)$ & & \\
\hline \multicolumn{6}{|c|}{ What is most common junk food you consume? } \\
\hline Fast food (momo, chowmin etc) & $60(49.2)$ & $57(46.7)$ & $5(4.1)$ & 0.305 & $0.581 * *$ \\
\hline Aerated drinks (coke, fanta) & $9(60.0)$ & $6(40.0)$ & $0(0.0)$ & & \\
\hline Street food (pakora, pani puri) & $22(52.4)$ & $19(45.2)$ & $1(2.4)$ & & \\
\hline Candies, biscuits, chips, noodles & $66(50.0)$ & $65(49.2)$ & $1(0.8)$ & & \\
\hline
\end{tabular}

Significant level at $<0.05 ; *$ likelihood ratio; ** Linear by linear

Table 4 depicts the association of junk food consumption pattern with BMI which reveals that time of junk food consumption is significantly associated with BMI with ( $p$ value 0.02 ) and expenses of the money on junk food consumption is also associated with BMI with ( $p$ value $0.006)$

\section{Discussion}

Junk food consumption has spread vigorously since the past decades especially among children and adolescents. Attractive advertisements and colorful packaging along with toy materials inside the package influences children to buy such products making a false claim of these foods being nutritious. The promotional schemes channeled through any means are so convincing and craving that speeds up in a while.

In this study majority of the adolescents were having BMI less than normal and were considered underweight. This finding is contrast with the finding of a study done in Saudi Arabia which revealed that $29.7 \%$ of adolescents consuming junk food were obese [7]. It suggests that junk food is one major factor associated with malnutrition either in terms of under or over nutrition.

According to the finding of present study majority of adolescents consume junk food in the school during break time as mid-day snack or lunch and students get easy access to these food items from the general stores around. The government of Nepal announced, on August 4, 2012, a ban on junk food like instant noodles, chips, soft drinks for school children as part of lunch throughout the country. Despite, government warning to cut off subsidies as penalties for those school not following the mandate, the ban is not properly implemented due to lack of effective guidelines and proper monitoring system [8]. It is suggested that local government should guide and monitor this system effectively so that junk food production and marketing is controlled and regulated.

According to the present study time of junk food consumption is significantly associated with BMI. The adolescents who consume junk food after school are found to be having BMI less than normal and considered underweight. This finding is supported by a study which explains that that high BMI was significantly associated 
with evening and night time fast food consumption [9]. This suggests that healthy food items should be offered to the adolescents at home thus restricting them from consuming junk food and they should also be warned by parents and teachers not to consume junk food on their way home and at home.

Study also revealed significant association in between the money spent in buying junk food with BMI. The adolescents who spend less than 20 Rs at a time in buying junk food are found to have less BMI and considered underweight. This suggests that those who consume street food, chips, instant noodles that are easily available at a low cost are considered to be food with less or no nutritive value. The recommendation is that street food stalls, general food stores should not be within the school premises and moreover parents should not provide money to their children as tiffin. Parents should set the limits over the pocket money and must prepare tiffin from home so they are not attracted and obliged to buy junk food.

Responsible precautions must be taken by the parents regarding the diet habits of their children and adoption of healthy life style so as to prevent or manage nutritional disorders among their children [10].

\section{Conclusion}

Based on the findings of study it can be concluded that junk food consumption is significantly associated with under nutrition or low Body Mass Index among adolescents. Only a limited numbers of adolescents have understood that excess consumption of junk food has negative effects on general health. It is required to provide awareness regarding the consequences of junk food consumption. It is also concluded that adolescents are attracted towards junk food because of its easy accessibility at a low cost. It is suggested that parents and school personnel should set the limit over consumption of junk food thus supporting government's mandate over ban of junk food.

\section{References}

[1] Merriam-Webster's. Online Dictionary. (2015): available at http://www.merriamwebster.com/dictionary/fast $\% 20$ food.

[2] Briefel RR, Wilson A, Gleason PM. Consumption of lownutrient, energy-dense foods and beverages at school, home, and other locations among school lunch participants and nonparticipants. J Am Diet Assoc. 2009; 79-90.

[3] Alfawaz HA. The relationship between fast food consumption and BMI among university female students. Pak Jn of Nutri. 2012; $11(5): 406-10$.

[4] Ashakiran A, Deepthi R. Fast foods and their impact on health. JKIMSU, 2012; 1 (2).

[5] Hesamedin AM, Mahnaz S, Ali M, Davoud S, Saharnaz Nejat, Abolghasem D. Factors Influencing Fast-Food Consumption Among Adolescents in Tehran: A Qualitative Study. Med J. $2016 ; 18(3)$.

[6] French S. A, Story M, Neumark D, Fulkerson J. A., Hannan P. Fast food restaurant use among adolescents. Associations with nutrient intake, food choices and behavioral and psychosocial variables. International Journal of Obesity. 2001; 25 (12):1823-33.

[7] Hala HA, Amany MB. Fast Food consumption associated with obesity /overweight/risk among University female student in Saudi Arabia. Pakistan Journal of Nutrition. 2015; 14 (8):51116.

[8] Naya patrika 2013, Junk food rumors in school (translated from Nepali), Editorial news Kathmandu.

[9] Trushna S, Geetanjali P, Sandhya PN, Bhavita Patel, Yash R, R. M. Shah. Assessment of Obesity, Overweight and Its Association with the Fast Food Consumption in Medical Students. Journal of Clinical and Diagnostic Research. 2014; 8 (5): 5-7.

[10] Monira A, Mohammed A, Muslim A, and Ali A Fast food intake and prevalence of obesity in school children in Riyadh City. Sudan J Paediatr. 2014; 14 (1): 71-80. 